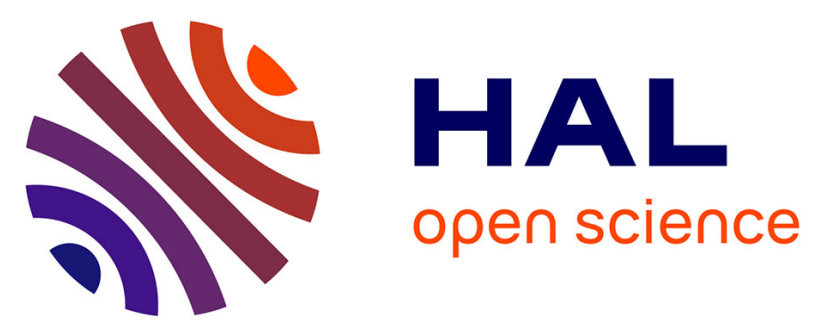

\title{
Quantitative Precipitation of Uranyl or Plutonyl Nitrate with N-(1-Adamantyl)acetamide in Nitric Acid Aqueous Solution
}

Gaël Loubert, Natacha Henry, Christophe Volkringer, Sylvain Duval, Christelle Tamain, Bénédicte Arab-Chapelet, Thibaud Delahaye, Thierry

Loiseau

\section{To cite this version:}

Gaël Loubert, Natacha Henry, Christophe Volkringer, Sylvain Duval, Christelle Tamain, et al.. Quantitative Precipitation of Uranyl or Plutonyl Nitrate with N-(1-Adamantyl)acetamide in Nitric Acid Aqueous Solution. Inorganic Chemistry, 2020, 59 (16), pp.11459-11468. 10.1021/acs.inorgchem.0c01258 . hal-03000819

HAL Id: hal-03000819 https://hal.science/hal-03000819

Submitted on 12 Nov 2020

HAL is a multi-disciplinary open access archive for the deposit and dissemination of scientific research documents, whether they are published or not. The documents may come from teaching and research institutions in France or abroad, or from public or private research centers.
L'archive ouverte pluridisciplinaire HAL, est destinée au dépôt et à la diffusion de documents scientifiques de niveau recherche, publiés ou non, émanant des établissements d'enseignement et de recherche français ou étrangers, des laboratoires publics ou privés. 


\section{Quantitative precipitation of uranyl or plutonyl nitrate with N-(1- adamantyl)acetamide in nitric acid aqueous solution}

Gaël Loubert, ${ }^{\mathrm{a}}$ Natacha Henry, ${ }^{\mathrm{a}}$ Christophe Volkringer, ${ }^{\mathrm{a}, \mathrm{b}}$ Sylvain Duval, ${ }^{\mathrm{a}}$ Christelle Tamain, ${ }^{\mathrm{c}}$ Bénédicte Arab-Chapelet, ${ }^{\mathrm{c}}$ Thibaud Delahaye, ${ }^{\mathrm{c}}$ Thierry Loiseau ${ }^{\mathrm{a}}$

Contribution from

${ }^{a}$ Unité de Catalyse et Chimie du Solide (UCCS) - UMR CNRS 8181, Université de Lille, Centrale Lille, Université d'Artois, F-59000 Lille, France.

${ }^{b}$ Institut Universitaire de France, 1 rue Descartes, 75231 Paris Cedex 05.

${ }^{\mathrm{c}}$ CEA, DES, ISEC, DMRC, Université de Montpellier, Marcoule, France.

* To whom correspondence should be addressed. E-mail: thierry.loiseau@univ-lille.fr, Phone: (33) 3204341 22, Fax: (33) 320434895.

To be submitted to Inorg. Chem.

First version April 28, 2020

Revised version July $1^{\text {st }}, 2020$

Last revision July $17^{\text {th }}, 2020$ 


\section{Table of Content (TOC) Graphic}

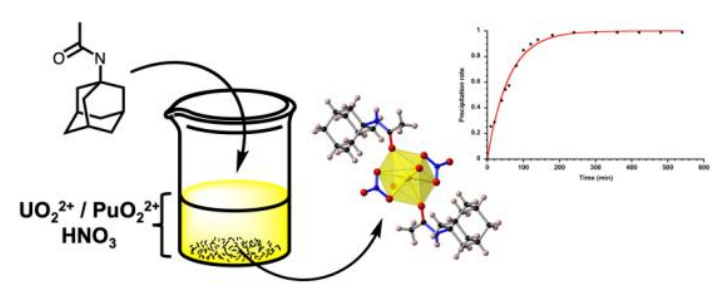

\section{Table of Content (TOC) Synopsis}

The N-(1-adamantyl)acetamide (L) ligand is used for recovering uranyl/plutonyl species from aqueous concentrated nitric acid solution, under the form of the crystalline complex $\left(\mathrm{AnO}_{2}\right)(\mathrm{L})_{2}\left(\mathrm{NO}_{3}\right)_{2} \cdot 2(\mathrm{~L})$, with high yield (up to $99 \%$ An). 
ABSTRACT: The reactivity of the N-(1-adamantyl)acetamide ligand ( $\mathrm{L}=$ adam $)$ has been evaluated as precipitating agent for the hexavalent uranyl cation ( $[\mathrm{U}]=20-60 \mathrm{~g} \cdot \mathrm{L}^{-1}$ ) in concentrated nitric acid aqueous solution (0.5-5 M). It results in the formation of a crystalline complex $\left(\mathrm{UO}_{2}\right)(\text { adam })_{2}\left(\mathrm{NO}_{3}\right)_{2} \cdot 2$ (adam) (1), in which the uranyl center is eight-fold coordinated to two chelating nitrate groups and two N-(1-adamantyl)acetamide (= adam) ligands through the oxygen atom of the amide function. Two other non-coordinating adam moieties are also observed in the crystal structure packing and interact through a hydrogen bond scheme with the uranyl-centered species. A similar molecular assembly has been obtained with the plutonyl(VI) cation, in the complex $\left(\mathrm{PuO}_{2}\right)(\text { adam })_{2}\left(\mathrm{NO}_{3}\right)_{2} \cdot 2$ (adam) (2). Precipitation studies indicate high $\left(\mathrm{UO}_{2}\right)(\text { adam })_{2}\left(\mathrm{NO}_{3}\right)_{2} \cdot 2$ (adam) formation yields (up to 99 $\%_{\mathrm{U}}$ for $\mathrm{L} / \mathrm{U}$ molecular ratio of 5/1) for $\mathrm{HNO}_{3}$ concentration in the 0.5-5 $\mathrm{M}$ range. However, the precipitation kinetics is rather slow and the reaction is completed after several hours (3-4 h). The calcination of the resulting solid under air atmosphere led to the formation of the $\mathrm{U}_{3} \mathrm{O}_{8}$ oxide from $400{ }^{\circ} \mathrm{C}$, through a transient phase $\mathrm{UO}_{2}$ fluorite-type (from $200{ }^{\circ} \mathrm{C}$ ).

Keywords: uranyl(VI), plutonyl(VI), N-(1-adamantyl)acetamide, precipitation study, coordination complex, single-crystal X-Ray diffraction, thermal analysis.

\section{Introduction}

The research of organic molecules for the actinides conversion into a solid form from the aqueous solution resulting from the dissolution of the spent nuclear fuel in nitric acid has been intensively investigated during the last decades. One of the current industrial process, PUREX $^{1,2}$, is based on the utilization of oxalate anion as a non-selective precipitating agent of actinides(III and IV). This process requires a redox adjustment before the conversion and leads to the quantitative precipitation of trivalent and/or tetravalent actinides into solid actinide oxalates used as oxide precursors (precipitation yield $>99 \%$ ) but is not efficient for hexavalent uranium precipitation. ${ }^{3-5}$ Alternative reprocessing routes have been studied and based on a precipitation without redox of uranyl by new organic molecules, which chemically interact specifically with the targeted actinides. In this context, a family containing pyrrolidone derivatives has been explored for their properties as precipitating agent toward the uranyl species. Indeed, in 2000, Ikeda and co-workers ${ }^{6}$ described the selective 
precipitation of $\mathrm{UO}_{2}{ }^{2+}$ cation with a yield of $68 \% \mathrm{U}$ by the N-cyclohexyl-2-pyrrolidone (NCP) molecule ${ }^{7}$ in concentrated nitric acid solutions, and opened a new investigation path for the research of novel precipitating agents with actinides. This NCP molecule has been found to be one of the most efficient ligands for the precipitation of uranyl solution and could be considered in a new process for recovering the actinides from spent nuclear fuel. ${ }^{8}$ The combination of a $\gamma$-butyrolactam group, with a cyclohexyl chain, is likely a good compromise that allows a good solubility of the free ligand in water and a relatively high hydrophobicity once the amide group is coordinated to metallic cations. The nature of the functionalization of the $\gamma$-butyrolactam has been examined in order to optimize the uranyl cation precipitation in concentrated nitric acid aqueous solution. These investigations gave rise to many reports of the structural characterizations of several pyrrolidone-based nitrate complexes with uranyl(VI). ${ }^{7,9,10}$ The reactivity of plutonyl(VI) cations has been also studied in order to analyze the formation of such pyrrolidone molecular assemblies, which may co-crystallize with the analogous uranyl(VI) element. ${ }^{11,12}$

The family of the alkylamides, to which pyrrolidone belongs, has also shown a potential interest as a specific extractant of the cationic uranyl $\left(\mathrm{UO}_{2}{ }^{2+}\right)$ and plutonium $\left(\mathrm{Pu}^{4+}\right)$ species for the separation of actinides from fission products. ${ }^{13,14}$ In this context, many investigations reported the formation of monoamide uranyl $\left(\mathrm{UO}_{2}\left(\mathrm{NO}_{3}\right)_{2} \mathrm{~L}_{2}\right)$ complexes or diamides $\left(\mathrm{UO}_{2}\left(\mathrm{NO}_{3}\right)_{2} \mathrm{~L}\right)$ complexes, in which the organic molecules $\mathrm{L}$ act as monodentate or polydentate ligands toward the actinide metallic center. ${ }^{15-36}$ The modification of the alkyl group (length and branching of the carbon chain) of the amide as well as functionalization offers the possibility to tune their extracting abilities.

In the present study, we studied another relative of monoamide to be considered in conversion processes. We report the efficient precipitation of uranyl cation in nitric acid aqueous solution by an acetamide-based molecule bearing an adamantyl group called $\mathrm{N}-(1-$ adamantyl)acetamide. With a cyclohexyl fragment completed by two other connected cyclohexane groups in an "armchair" configuration, the nitrogen atom is still functionalized by a non polar aliphatic cycle, as for the NCP. To counter balance the increase of the molecule hydrophobicity, the butyrolactam is removed (Figure 1). 

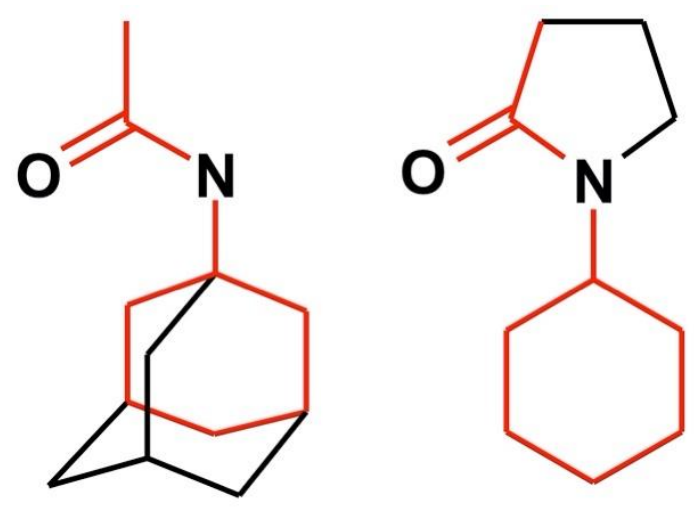

Figure 1: Schematic representation of the studied monoamide N-(1-adamantyl)acetamide (left) and Ncyclohexyl-2-pyrrolidone (right). The common carbon backbone of the two ligand types is indicated in red.

This work deals with the precipitation of uranyl(VI) cation with the $\mathrm{N}-(1-$ adamantyl)acetamide molecule $(\mathrm{N}$-(1-adamantyl)acetamide $=$ adam $)$ in nitric acid aqueous solution. The ability of this ligand to precipitate the uranyl cation has been studied by investigating different parameters, such as molar ligand/U ratio, uranium and nitric acid concentrations and reaction time. The structure and speciation of the solid were also investigated from the synthesis and crystal structure characterization of the coordination complex of the actinyl nitrate $\mathrm{N}$-(1-adamantyl)acetamide, $\left(\mathrm{UO}_{2}\right)(\text { adam })_{2}\left(\mathrm{NO}_{3}\right)_{2} \cdot 2$ (adam). Its analogous single-crystal structure has been investigated with plutonyl(VI) cation (compound (2)). Finally, the precipitating routes has been considered to recover actinides from aqueous solutions in order to elaborate actinide oxides. The thermal treatment into uranium oxide of the resulting crystalline precipitate $\left(\mathrm{UO}_{2}\right)(\text { adam })_{2}\left(\mathrm{NO}_{3}\right)_{2} \cdot 2$ (adam) (1) was studied by thermogravimetric method and X-ray thermodiffraction techniques.

\section{Experimental Section}

Reagents. Caution! Uranium and plutonium precursors are radioactive and chemically toxic reactants, so precautions with suitable care and protection for handling such substances have been followed. The manipulation of plutonium reactant has been carried out at the ATALANTE facility (CEA-Marcoule, France). Because of the highly radioactive nature of plutonium, the experiments involving this element were carried out in glove box with very 
restrictive protocols. Initially, $\mathrm{Pu}(\mathrm{IV})$ nitrate solution $\left({ }^{239} \mathrm{Pu}\right)$ was prepared by dissolving the corresponding oxide, $\mathrm{PuO}_{2}$, in a nitrofluorhydric solution $\left(\mathrm{HNO}_{3} 10 \mathrm{M}-\mathrm{HF} 0.05 \mathrm{M}\right)$ followed by a purification step on a DOWEX resin. Then, the resulting $\mathrm{Pu}(\mathrm{IV})$ nitrate solution was oxidized to $\mathrm{Pu}(\mathrm{VI})$ nitrate solution by addition of silver oxide $\mathrm{AgO}$ (molar ratio $\mathrm{Ag} / \mathrm{Pu}=2 / 1$ ). The reduced form of $\mathrm{Ag}^{+}$ion was eliminated by precipitation with one equivalent of hydrochloric acid to form $\mathrm{AgCl}$. The resulting plutonyl(VI) nitrate aqueous solution was filtrated under vacuum and characterized by UV-Vis spectroscopy in order to determine the final plutonium concentration.

The other following reactants were used: uranyl nitrate hexahydrate $\left(\mathrm{UO}_{2}\left(\mathrm{NO}_{3}\right)_{2} \cdot 6 \mathrm{H}_{2} \mathrm{O}\right.$, Merck, $99 \%)$, N-(1-adamantyl)acetamide $\left(\mathrm{C}_{12} \mathrm{H}_{19} \mathrm{NO}\right.$, noted adam, Alfa Aesar, $\left.98 \%\right)$, nitric acid $\left(\mathrm{HNO}_{3}, 68 \%, \mathrm{VWR}\right)$ and deionized water. The chemical reactants were commercially available and were used without any further purification.

\section{Compounds $1 \& 2$ syntheses}

$\left(\mathrm{UO}_{2}\right)(\text { adam })_{2}\left(\mathrm{NO}_{3}\right)_{2} \cdot \mathbf{2}($ adam $)(\mathbf{1})$ : A mixture of $200 \mathrm{mg}(0.4 \mathrm{mmol}) \mathrm{UO}_{2}\left(\mathrm{NO}_{3}\right)_{2} \cdot 6 \mathrm{H}_{2} \mathrm{O}, 75$ $\mathrm{mg}(0.4 \mathrm{mmol}) \mathrm{N}$-(1-adamantyl)acetamide and $10 \mathrm{~mL}$ aqueous $\mathrm{HNO}_{3}(0.5 \mathrm{M})$ was placed in a glass tube and then heated at $50^{\circ} \mathrm{C}$ for 24 hours. The resulting yellow crystalline powder was then filtered off, washed with water and dried at room temperature in air atmosphere. Yield reaction was $24.4 \%_{U}$ from these synthetic conditions (here, initial Ligand/U ratio of 1/1). 1 was analyzed by scanning electron microscope showing well-shaped multi-facetted bulky crystals of 10-150 $\mu \mathrm{m}$ size (Figure S1a).

$\left(\mathbf{P u O}_{2}\right)(\text { adam })_{2}\left(\mathrm{NO}_{3}\right)_{2} \cdot \mathbf{2}$ (adam) (2): A mixture of $162 \mathrm{mg} \quad(0.84 \mathrm{mmol}) \quad \mathrm{N}-(1-$ adamantyl)acetamide and $5 \mathrm{~mL}$ plutonyl(VI) nitrate aqueous solution $([\mathrm{Pu}]=0.084 \mathrm{M}$; $\left[\mathrm{HNO}_{3}\right]=1 \mathrm{M}$ ) was placed in a glass tube and then left at room temperature for 16 hours. Yield reaction was $49 \%$ Pu. 2 was analyzed by scanning electron microscope showing wellshaped multi-facetted bulky crystals of 5-50 $\mu \mathrm{m}$ size (Figure S1b). Due to the highly plutonium radiotoxicity, limited characterizations have been carried out with this element: they included single-crystal X-ray diffraction, powder X-ray diffraction (Figure S2b) and one batch of precipitation (from $[\mathrm{Pu}]=20 \mathrm{~g} \cdot \mathrm{L}^{-1}$ ) analyses.

\section{Single-crystal X-ray diffraction}

Crystal of compound $\mathbf{1}$ was selected under polarizing optical microscope and glued on a glass fiber for a single-crystal X-ray diffraction experiment. X-ray intensity data were collected on 
a Bruker DUO-APEX2 CCD area-detector diffractometer using Mo- $K_{\alpha}$ radiation $(\lambda=$ $0.71073 \AA$ ) with an optical fiber as collimator. Several sets of narrow data frames (20 s per frame) were collected with $\omega$ scans. A crystal of $\mathbf{2}$ was mounted on MicroMount patented by MiTeGen, inserted into a goniometer base. For confinement purpose, a MicroRT capillary was then drawn over the sample and onto the base, where it was sealed by adhesive. The single-crystal XRD intensities were measured on a Nonius four-circle diffractometer equipped with an Apex II detector. The instrument was equipped with a fine-focus Mo-target X-ray tube $(\lambda=0.71073 \AA$ ) operated at $1500 \mathrm{~W}$. Data reduction was accomplished using SAINT V7.53a. ${ }^{37}$ The substantial redundancy in data allowed a semi-empirical absorption correction (SADABS V2.10 ${ }^{38}$ ) to be applied, on the basis of multiple measurements of equivalent reflections. The structure of $\mathbf{1}$ was solved by direct methods, developed by successive difference Fourier syntheses, and refined by full-matrix least-squares on all data using SHELX program suites, ${ }^{39}$ implemented in the OLEX $2^{40}$ interface. Crystals of compound 2 were systematically twinned (merohedral twinning) and were treated by means of the JANA2006 software suite. ${ }^{41}$ For this compound 2, the orientation matrix for the two domains was $100 ;-0.1172-10 ;-0.470-1$, with 49.6(7) \% of domain I, and consequently 50.4(7) \% of domain II.

The crystal data are given in Table 1. Supporting information is available in CIF format. CCDC numbers: 1987462 for 1, 1987465 for 2, contain the supplementary crystallographic data for this paper. These data can be obtained free of charge from The Cambridge Crystallographic Data Centre via www.ccdc.cam.ac.uk/data_request/cif.

Table 1. Crystal data and structure refinement for compounds $1 \& 2$.

\begin{tabular}{|l|l|l|}
\hline & \multicolumn{1}{|c|}{$\mathbf{1}$} & \multicolumn{1}{c|}{2} \\
\hline Formula & $\mathrm{C}_{48} \mathrm{H}_{76} \mathrm{~N}_{6} \mathrm{O}_{12} \mathrm{U}$ & $\mathrm{C}_{48} \mathrm{H}_{76} \mathrm{~N}_{6} \mathrm{O}_{12} \mathrm{Pu}$ \\
\hline Formula weight & 1167.17 & 1173.2 \\
\hline Temperature/K & 296 & 293 \\
\hline Crystal type & yellow block & yellow block \\
\hline Crystal size/mm & $0.25 \times 0.20 \times 0.16$ & $0.06 \times 0.05 \times 0.04$ \\
\hline Crystal system & triclinic & triclinic \\
\hline Space group & $P-1$ & $P-1$ \\
\hline$a / \AA$ & $10.1363(3)$ & $10.0759(3)$ \\
\hline$b / \AA$ & $11.5945(3)$ & $11.5308(3)$ \\
\hline$c / \AA$ & $12.8737(4)$ & $12.5976(4)$ \\
\hline$\alpha /^{\circ}$ & $65.038(1)$ & $65.646(1)$ \\
\hline$\beta /{ }^{\circ}$ & $70.866(1)$ & $71.250(1)$ \\
\hline$\gamma^{\circ}$ & $79.406(1)$ & $79.151(1)$ \\
\hline Volume $/ \AA^{3}$ & $1294.05(7)$ & $1259.99(6)$ \\
\hline
\end{tabular}




\begin{tabular}{|l|l|l|}
\hline $\mathrm{Z}, \rho_{\text {calculated }} /{\mathrm{g} . \mathrm{cm}^{-3}}^{-3}$ & $1,1.498$ & $1,1.546$ \\
\hline$\mu / \mathrm{mm}^{-1}$ & 3.200 & 1.374 \\
\hline$\Theta$ range/ $^{\circ}$ & $1.82-30.50$ & $1.84-29.87$ \\
\hline Limiting indices & $-14 \leq h \leq 14$ & $-14 \leq h \leq 13$ \\
& $-16 \leq k \leq 16$ & $-16 \leq k \leq 16$ \\
& $-18 \leq l \leq 18$ & $-16 \leq l \leq 17$ \\
\hline Collected reflections & 34849 & 17665 \\
\hline Unique reflections & 7895 & 10679 \\
& {$[\mathrm{R}(\mathrm{int})=0.0408]$} & {$[\mathrm{R}(\mathrm{int})=0.0464]$} \\
\hline Parameters & 306 & 305 \\
\hline Goodness-of-fit on $\mathrm{F}^{2}$ & 1.063 & 1.20 \\
\hline Final R indices $[\mathrm{I}>2 \sigma(\mathrm{I})]$ & $\mathrm{R} 1=0.0225$ & $\mathrm{R} 1=0.0387$ \\
& $\mathrm{wR} 2=0.0549$ & $\mathrm{wR} 2=0.0369$ \\
\hline R indices (all data) & $\mathrm{R} 1=0.0228$ & $\mathrm{R} 1=0.0455$ \\
& $\mathrm{wR} 2=0.0550$ & $\mathrm{wR} 2=0.0381$ \\
\hline Largest diff. peak and hole/e. $\AA^{-3}$ & 1.151 and -0.419 & 1.15 and -1.43 \\
\hline
\end{tabular}

ICP-AES (Inductively Coupled Plasma Atomic Emission Spectroscopy).

The supernatant aqueous solutions after reaction of the uranyl nitrate precursor with the organic adam ligand have been analyzed by using a Vista-PRO VARIAN spectrometer. A fraction of the supernatant solution $(10 \mu \mathrm{L})$ was extracted, then diluted 1000 times with deionized water. The remaining uranium concentration was then directly analyzed with the ICP-AES technique. The ICP measurement was accumulated routinely three times and then merged. The uranium contents are given with uncertainties of $5 \%$.

\section{Powder XRD}

X-ray powder diffraction was performed on Bruker D8 Advance diffractometer (LynxEye detector) in a Bragg-Brentano $\theta-\theta$ mode using $\mathrm{Cu}-\mathrm{K}_{\alpha}$ radiation. Each powder pattern was recorded within an angular range of $5-50^{\circ}$ in $2 \theta$, with steps of $0.02^{\circ}$ and counting time of $0.5 \mathrm{~s}$ per step.

\section{Scanning electron microscopy}

The SEM analyses of uranium compound were performed on a Hitachi-S3400N microscope, equipped with a tungsten filament (acceleration voltage $=15 \mathrm{kV}$, secondary electron mode, working distance $=5$ to $10 \mathrm{~mm}$ ). Plutonium compound was studied on a Zeiss Supra 55/55VP field-emission scanning electron microscope (acceleration voltage $=5 \mathrm{kV}$, secondary electron 
mode, working distance 5 to $10 \mathrm{~mm}$, diaphragm $=30 \mu \mathrm{m}$ ). Both with uranium and plutonium based samples, powders were coated with gold prior to the analysis.

\section{Specific surface area measurement}

The specific surface area was measured at $77 \mathrm{~K}$ by the BET method with a MICROMERITICS ASAP 2020 (surface area and porosity analyzer). About $100 \mathrm{mg}$ of sample has been used and degassed at $200^{\circ} \mathrm{C}$ under vacuum. For surface area calculations, we used krypton gas adsorption and BET model was applied in the $p / p_{0}$ range of 0.01-0.2.

\section{Thermal analysis}

Thermogravimetric analysis was performed on a thermoanalyzer 92 SETARAM TGA up to $800{ }^{\circ} \mathrm{C}$, in air, with a heating rate of $5{ }^{\circ} \mathrm{C} \cdot \mathrm{min}^{-1}$.

X-ray thermodiffractometry was performed under $51 . \mathrm{h}^{-1}$ air flow in an Anton Paar HTK1200N of a D8 Advance Bruker diffractometer ( $\theta-\theta$ mode, $\mathrm{CuK} \alpha$ radiation) equipped with a Vantec1 linear position sensitive detector (PSD). Each powder pattern was recorded in the range 5-60

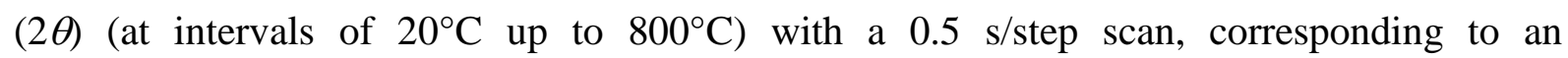
approximate duration of $30 \mathrm{mn}$.

\section{Visible spectroscopy}

The plutonium solutions were determined by Vis spectroscopy using a spectrophotometer VARIAN CARY 6000i, the optical signal is transmitted through optical fibers (10 m length, Hellma) from the disposable UV-cuvette (PMMA, $1 \mathrm{~cm}$ optical path) inside the glove-box to the spectrophotometer placed outside. Solution is scanned from 350 to $900 \mathrm{~nm}$ with a speed of $300 \mathrm{~nm} / \mathrm{min}$, a measuring range of $1 \mathrm{~nm}$ and a gap width of $1.5 \mathrm{~nm}$. Uncertainties of the uranium content are estimated to be $10 \%$.

\section{Results and discussion}

\section{Structure Description}

The association of the $\mathrm{N}-(1$-adamantyl)acetamide ligand with actinyl(VI) cations gives rise to the formation of a coordination complex of type $\left(\mathrm{AnO}_{2}\right)(\text { adam })_{2}\left(\mathrm{NO}_{3}\right)_{2} \cdot 2$ (adam), where $\mathrm{An}$ is $\mathrm{U}$ in $\mathbf{1}$, and $\mathrm{Pu}$ in $\mathbf{2}$. Their crystal structures are similar and composed of a molecular moiety 
containing actinyl center bonded to two $\mathrm{N}$-(1-adamantyl)acetamide and two bidentate nitrate groups (Figure 2). Within this discrete entity, the actinyl center sits on a special position $1 / 21 / 2$ 0 (inversion center, $1 e$ ) and holds an eight-fold hexagonal bipyramidal coordination, with the typical double trans uranyl $(\mathrm{U}=\mathrm{O}=1.763(2) \AA)$, or plutonyl $(\mathrm{Pu}=\mathrm{O}=1.736(3) \AA)$ bondings. The two nitrate groups are placed in trans position within the equatorial hexagonal plane, adopting a chelating connection mode, with U-O bonding lengths of 2.514(2) and 2.536(2) $\AA$ in 1, and Pu-O bonding lengths of 2.492(3) and 2.519(3) $\AA$ in 2. The two remaining An-O bondings correspond to the monodentate linkage with the amide oxygen atom of the organic ligand $(\mathrm{U}-\mathrm{O}=2.366(1) \AA$; $\mathrm{Pu}-\mathrm{O}=2.368(2) \AA)$. It is interesting to notice that the An- $\mathrm{O}_{\text {nitrate }}$ bond lengths decrease from uranyl to plutonyl as expected with the radius contraction, but the An- $\mathrm{O}_{\text {amide }}$ bond length is almost identical. For complex $\mathbf{1}$, the $\mathrm{U}-\mathrm{O}_{\text {nitrate }}(\approx 2.52 \AA)$ and U$\mathrm{O}_{\text {amide }}(\approx 2.36 \AA$ ) bond distances are typical for uranyl, according to the Cambridge Structural Database (Release v.5.41 November 2019). For the plutonyl complex 2, only three compounds have been referenced in the presence of chelating nitrate groups, with the $\mathrm{Pu}$ $\mathrm{O}_{\text {nitrate }}$ bond distances in the range 2.472-2.519 $\AA^{12,42,43}$ and $\mathrm{Pu}-\mathrm{O}_{\text {amide }}$ bond distance equal to $2.377 \AA{ }^{12}$ close to what is observed here. Within the nitrate groups, the N-O bond distances are 1.257(3) and 1.268(3) $\AA$, for the oxygen atoms involved with the uranyl center in $\mathbf{1}$. The terminal N-O bonding distance is shorter, with a value of $1.215(3) \AA$, as expected. ${ }^{7,16}$ The distances within the nitrate group in 2, are 1.270(4) $\AA$ for the oxygen atoms linked to the plutonyl center and 1.219(6) $\AA$ for the terminal N-O bonding.

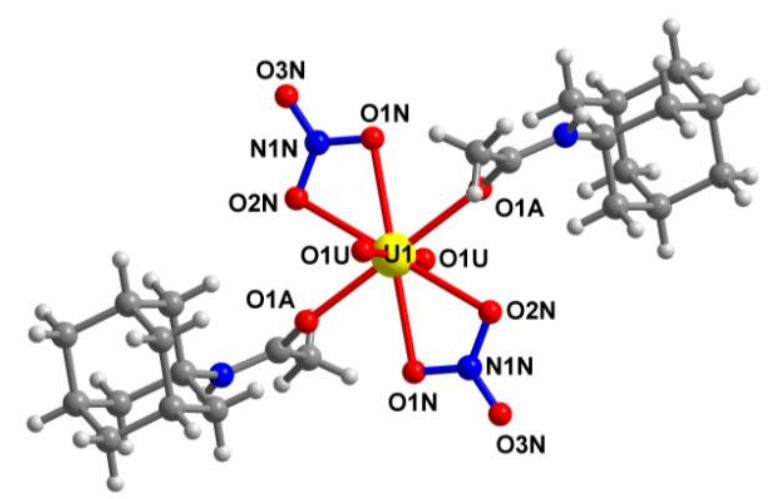




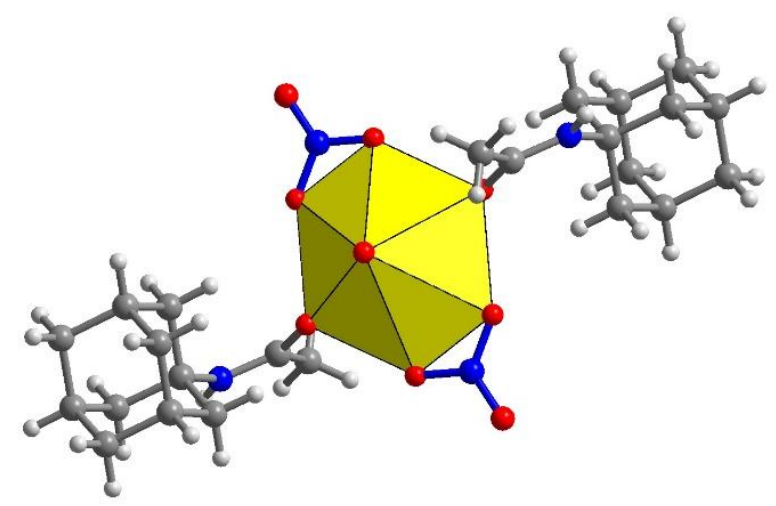

Figure 2: Representations of the molecular complex of the uranyl $\mathrm{N}$-(1-adamantyl)acetamide $\mathrm{UO}_{2}(\text { adam })_{2}\left(\mathrm{NO}_{3}\right)_{2} \cdot 2$ (adam) (1). Yellow circle: uranium(VI); red circle: oxygen; blue circle: nitrogen; grey circle: carbon; light grey circle: hydrogen. The molecular complex of the plutonyl analog (2) is identical and shown in Figure S4.

The crystal structure consists of the packing of such neutral $\left[\left(\mathrm{AnO}_{2}\right)(\text { adam })_{2}\left(\mathrm{NO}_{3}\right)_{2}\right]$ moieties via Van der Waals and hydrogen bond interactions. Additional non-coordinating N-(1adamantyl)acetamide molecules have been revealed from the single-crystal XRD analysis and are intercalated between the actinyl coordination complexes, along the [101] direction (Figure S3), resulting in an unexpected $\mathrm{L} / \mathrm{An}$ ratio of $4(\mathrm{~L}=\mathrm{N}$-(1-adamantyl)acetamide). One notices the difference of the carbonyl bond $\mathrm{C}=\mathrm{O}$ lengths, which differs in the free state $(\mathrm{C}=\mathrm{O}=$ 1.224(4) $\AA$ for $\mathbf{1} ; 1.232(5) \AA$ for 2$)$ and the coordinated state $(\mathrm{C}=\mathrm{O}=1.252(2) \AA$ for $\mathbf{1} ; \mathrm{C}=\mathrm{O}=$ 1.260(4) $\AA$ for 2). This increase can be explained by the improved electronic delocalization from the ligand to the metallic cation combined with the conjugated nitrogen atom allowing a charge delocalization from the nitrogen doublet towards the $\mathrm{C}=\mathrm{O}$ function and towards the cation. The phenomenon is also responsible for the slight shorten of the $\mathrm{C}-\mathrm{N}$ bond (Table 2) of the monoamide with 1.320(3) $\AA$ for $\mathbf{1}$, and 1.321(5) $\AA$ for $\mathbf{2}$ for the coordinating molecule, and 1.336(3) $\AA$ and 1.345(5) $\AA$ for $\mathbf{1}$ and 2, respectively for the non-coordinating ligand. The free $\mathrm{N}$-(1-adamantyl)acetamide species interacts through hydrogen bonds between its $\mathrm{N}-\mathrm{H}$ group and the terminal oxygen atom of the nitrate group $(\approx 2.21 \AA)$ as well as the $\mathrm{C}=\mathrm{O}$ group with the N-H group $(\approx 2.03 \AA$ ) from an adjacent linked $\mathrm{N}$-(1-adamantyl)acetamide molecule (Figure 3). 
Table 2: Summary of the interatomic bond distances related to the C-N length within the organic ligand, for the compounds $1 \& 2$.

\begin{tabular}{|c|c|c|}
\hline C-N bond length $(\AA)$ & $\begin{array}{c}\text { Bounded } \\
\text { monoamide }\end{array}$ & $\begin{array}{c}\text { Free } \\
\text { monoamide }\end{array}$ \\
\hline $\mathrm{U}(\mathrm{VI})$-adam (1) & $1.320(3)$ & $1.336(3)$ \\
\hline $\mathrm{Pu}(\mathrm{VI})$-adam (2) & $1.321(5)$ & $1.345(5)$ \\
\hline
\end{tabular}

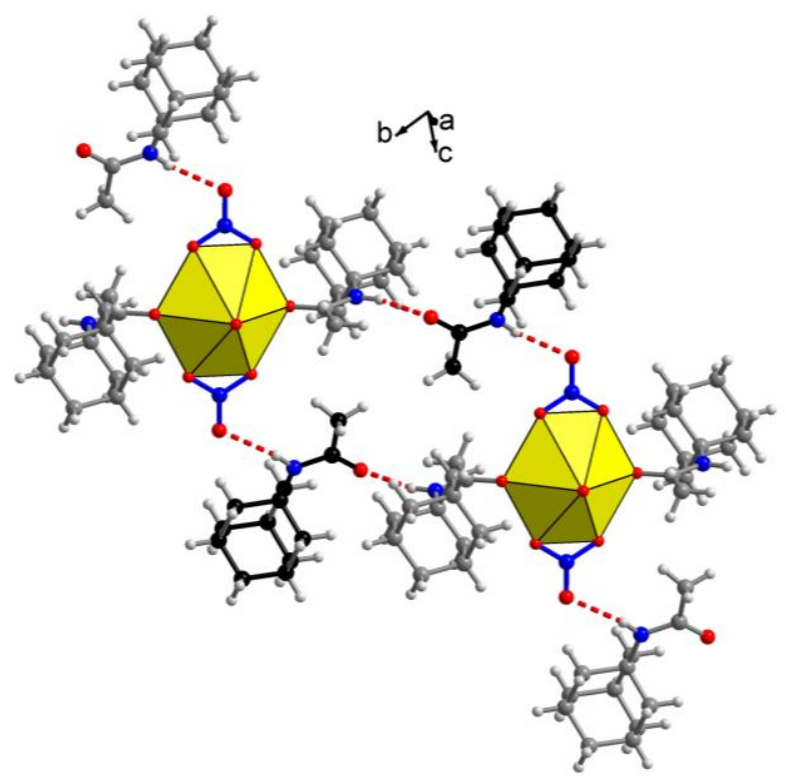

Figure 3: View of the hydrogen bond network (dotted red line) in compound $\mathrm{AnO}_{2}(\text { adam })_{2}\left(\mathrm{NO}_{3}\right)_{2} \cdot 2$ (adam) (1-2), with the connection modes between free $\mathrm{N}-(1$ adamantyl)acetamide molecules and the coordination molecular complex $\left[\mathrm{AnO}_{2}(\text { adam })_{2}\left(\mathrm{NO}_{3}\right)_{2}\right]$ via $\mathrm{N}$ $\mathrm{H} \cdots \mathrm{O}_{\text {nitrate }}$ and $\mathrm{N}-\mathrm{H} \cdots \mathrm{O}-\mathrm{C}$ bonding. Yellow circle: uranium(VI) or plutonium(VI); red circle: oxygen; blue circle: nitrogen; grey/black circle: carbon; light grey circle: hydrogen.

\section{Precipitation study of the actinyl N-(1-adamantyl)alkylamide nitrate complexes}

The precipitation yield of uranyl nitrate with $\mathrm{N}$-(1-adamantyl)acetamide (L) was firstly investigated in nitric acid aqueous solution. The initial uranium and nitric acid concentrations were adjusted to $20 \mathrm{~g} . \mathrm{L}^{-1}$ and $0.5 \mathrm{M}$, respectively. The molar ratio of amide over uranium concentrations $\mathrm{L} / \mathrm{U}$ range from 0.25 to 6 . The precipitation process followed the synthetic route described in the experimental section for the preparation of complex $\mathbf{1}$ under static conditions (without magnetic stirring), after heating at $50{ }^{\circ} \mathrm{C}$ for 24 hours. The supernatant solution at the end of the precipitation was separated from the solid and analyzed by ICP-AES to measure the concentration of non-converted uranyl species, and thus the quantitative yield of the precipitation reaction for the formation of complex 1. For each synthesis, the 
composition of the solid was analyzed by powder X-Ray diffraction to ensure it is singlephased. One example of the comparison of the experimental XRD pattern to the calculated one (from the single-crystal study) is given Figure S2a of the supporting information. The solid was also analyzed by IR spectroscopy (see Figure S8 of the supporting information). Figure 4 indicates the evolution of the yield of the formation of $\left(\mathrm{UO}_{2}\right)(\text { adam })_{2}\left(\mathrm{NO}_{3}\right)_{2} \cdot 2$ (adam) (1) precipitate as a function of $\mathrm{L} / \mathrm{U}$ molar ratio. It shows a linear increase of the yield between $\mathrm{L} / \mathrm{U}=0.25$ and $\mathrm{L} / \mathrm{U}=4$ (yield reaction $92 \%_{\mathrm{U}}$ ), and then a slight increase for $\mathrm{L} / \mathrm{U}>4,96 \%$ and $99 \%$ for $\mathrm{L} / \mathrm{U}=5$ and 6 respectively. The optimum ratio $\mathrm{L} / \mathrm{U}=4$ is expected since it is directly related to that of the stoichiometry observed in the crystal structure of complex $\mathbf{1}$. For the $\mathrm{U} / \mathrm{L}=6$ ratio value, the remaining uranium concentration in the supernatant solution is lower than 0.2 g. $\mathrm{L}^{-1}$.

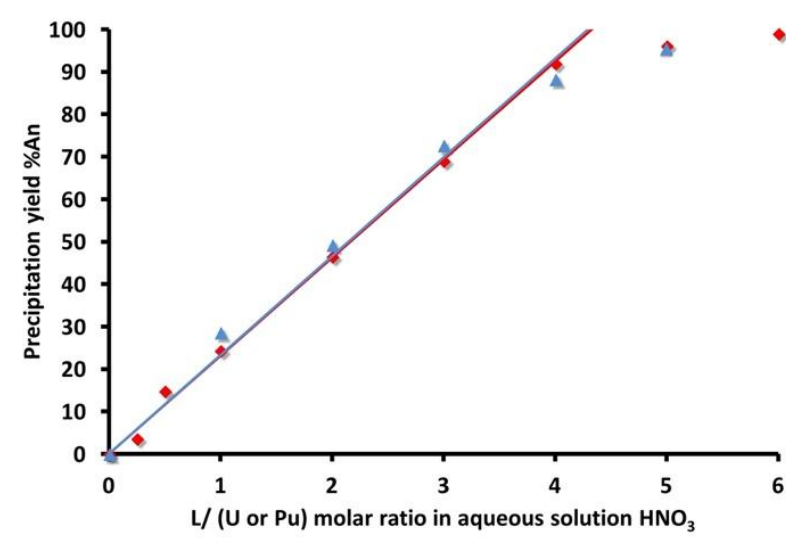

Figure 4: Yields of the formation of $\left(\mathrm{AnO}_{2}\right)(\text { adam })_{2}\left(\mathrm{NO}_{3}\right)_{2} \cdot 2$ (adam) (U (1): red lozenge; $\mathrm{Pu}(2)$ : blue triangles) precipitates as a function of $\mathrm{L} / \mathrm{U}$ molar ratio in $\mathrm{HNO}_{3} 0.5 \mathrm{M}$ for uranyl aqueous solution and $\mathrm{HNO}_{3}(1 \mathrm{M})$ for plutonyl aqueous solution $\left([\mathrm{U}]=[\mathrm{Pu}]=20 \mathrm{~g} \cdot \mathrm{L}^{-1}\right)$.

Due to the structural similarities observed for the complex $\left(\mathrm{AnO}_{2}\right)(\text { adam })_{2}\left(\mathrm{NO}_{3}\right)_{2} \cdot 2$ (adam) involving uranium(VI) (1) or plutonium(VI) (2), the same experiment has been performed from an aqueous solution containing plutonyl nitrate species with a concentration of 20 g.L. $\mathrm{L}^{-1}$ at ambient temperature. For safety reasons, it was not possible to carry out the experiment at $50{ }^{\circ} \mathrm{C}$ as for uranium. Moreover, the nitric acid concentration was set to $1 \mathrm{M}$ to preclude plutonium hydrolysis reaction. The molar ratio of the $\mathrm{N}$-(1-adamantyl)acetamide $(\mathrm{L})$ over $\mathrm{Pu}$ contents was ranging from 1 to 5, and the mixture was left static for 16 hours. The comparison of the experimental XRD pattern to the calculated one (from the single-crystal study) given Figure S2b of the supporting information indicates the formation of the same phase as the one 
described previously. The reaction yield for the formation of complex $\left(\mathrm{PuO}_{2}\right)(\text { adam })_{2}\left(\mathrm{NO}_{3}\right)_{2} \cdot 2$ (adam) (2) was estimated on the basis of the concentration of plutonium remaining in the aqueous solution, by using UV-Vis spectroscopy. The evolution of the plutonium precipitation yield is alike the uranyl one: linear progression between $\mathrm{L} / \mathrm{Pu}=$ 1 and $\mathrm{L} / \mathrm{Pu}=4$ ratios (Figure 4 ), with a upper value up to $88 \% \mathrm{Pu}$ with a slight increase for higher ratio than stoichiometry $\left(\mathrm{L} / \mathrm{Pu}=5,95 \%_{\mathrm{Pu}}\right)$.

For the formation of the uranyl $\mathrm{N}$-(1-adamantyl)acetamide nitrate complex (1), the influence of the acidity of the aqueous solution has been then examined for nitric acid concentrations ranging from 0 to $5 \mathrm{M}$ with $\mathrm{L} / \mathrm{U}$ molar ratio of 5 (after reaction at $50^{\circ} \mathrm{C}$ for 24 hours). Without $\mathrm{HNO}_{3}$, the precipitation yield is found to be about $88 \%_{\mathrm{U}}$. The addition of nitric acid favors the crystallization of compound 1 resulting in increasing acidity, and by providing an excess of nitrate anion to the reaction medium. An increase of the precipitation yield up to $99 \%_{\mathrm{U}}$ for $\mathrm{HNO}_{3}$ above $1 \mathrm{M}$, (Figure 5). This result as well as the conservation of the XRD patterns indicate that such uranyl N-(1-adamantyl)acetamide nitrate complex (1) exhibits a very good stability toward nitric acidity, as it is required in the actinide recycling process.

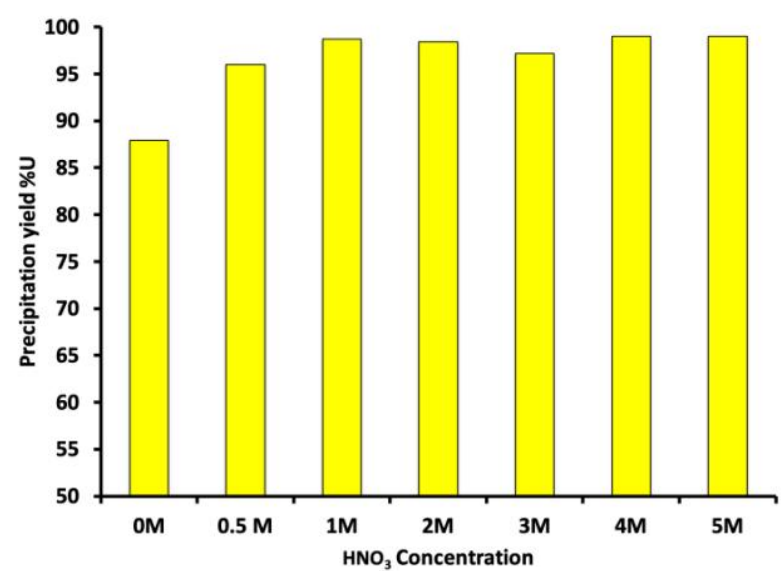

Figure 5: Yield of the formation of $\left(\mathrm{UO}_{2}\right)(\text { adam })_{2}\left(\mathrm{NO}_{3}\right)_{2} \cdot 2$ (adam) $(\mathbf{1})$ precipitate as a function of the $\mathrm{HNO}_{3}$ concentration for L/U molar ratio 5/1.

The concentration of uranium in aqueous solution with nitric acid $0.5 \mathrm{M}$ was then studied for 20, 40 and $60 \mathrm{~g} . \mathrm{L}^{-1}$. For the L/U ratio of 5 , the precipitation yield remains approximately stable even if it slightly increases with the uranium concentration, from 96 up to $98 \% \mathrm{U}$ (Figure S5). 


\section{Precipitation kinetics of the uranyl N-(1-adamantyl)acetamide nitrate complex (1)}

The kinetics of the precipitation of the complex $\mathbf{1}$ was analyzed for three uranium concentrations, 20, 40 and 60 g. $\mathrm{L}^{-1}$ in $\mathrm{HNO}_{3} 0.5 \mathrm{M}$. The ligand was added at $\mathrm{t}=0$ to the uranyl nitrate aqueous solution and then a $10 \mu \mathrm{L}$ sample of supernatant liquid was withdrawn at different times in order to measure by ICP the remaining uranium concentration in the liquid phase. The Avrami-Erofe'ev equation ${ }^{42,44}$ involving an exponential evolution of type $\alpha=1-$ $\exp \left[-(k \mathrm{t})^{n}\right]$ was used to help rationalize the data. For this model, $\alpha$ is the reaction rate (in our case, related to the precipitation yield of uranyl complex $\mathbf{1}$ ), $k$ is a kinetics constant and $n$ is an Avrami coefficient. Although this kinetics model was initially used for the specific case of solid-solid transitions, it is now widely used to describe the crystalline formation of different types of materials (for instance: zeolites, ${ }^{45,46}$ organically templated metal phosphates, ${ }^{47-49}$ coordination polymers, metal-organic frameworks, $\left.{ }^{50-52} \ldots\right)$. The expression is quite convenient to extract kinetics constants of the formation of crystalline products. However, the significance of the fitted Avrami parameter could be questionable and then considered with caution, if one considers the heterogeneous crystallization from a solution to a solid, as it occurs in our precipitation experiment of uranyl $\mathrm{N}$-(1-adamantyl)acetamide nitrate complex. The fit accuracy of kinetics curves has been evaluated using the Sharp-Hancock method, ${ }^{53}$ corresponding to the linear transformation of the Avrami-Erofe'ev equation, as $\ln [-\ln (1-\alpha)]$ $=n \ln (k)+n \ln (\mathrm{t})$. The kinetics parameters obtained for the different precipitations with various conditions (static/stirring; [U] varying from 20 to 60 g. $\mathrm{L}^{-1}$ ) are summarized in the Table 3. The Avrami-Erofe'ev and Sharp-Hancock plots are presented in the Figure 6 only for [U] $=$ 20 g. $\mathrm{L}^{-1}$. Other kinetics curves for $[\mathrm{U}]=40$ and 60 g. $\mathrm{L}^{-1}$, are given in the Supplementary Information (Figures S6 \& S7).

At $[\mathrm{U}]=20 \mathrm{~g} \cdot \mathrm{L}^{-1}$, under static condition (without magnetic stirring; Figure 6), the maximum precipitation yield is not reached after 10 hours, since only $87 \%$ of uranium crystallized. The corresponding fitted values $k$ and $n$ are $0.0049(3) \min ^{-1}$ and $0.71(5)$, respectively. The influence of stirring the aqueous solution mixture has been evaluated by means of rotating magnet (rotation speed: $750 \mathrm{rpm}$ ). The precipitation kinetics increases drastically under magnetic stirring reaching the maximum yield value of $99 \%_{\mathrm{U}}$ after 4 hours of reaction at $50^{\circ} \mathrm{C}$. The corresponding $k$ and $n$ values are $0.0168(7) \mathrm{min}^{-1}$ and $0.99(7)$, respectively. The effect of stirring increases the precipitation kinetics by a factor $\approx 3.5$ in these conditions. The 
same behavior is observed for higher uranium concentrations, but less contrasted. The $k$ parameters are 0.0101(4) $\mathrm{min}^{-1}$ (static) and 0.0203(6) $\mathrm{min}^{-1}$ (stirring) for [U] $=40 \mathrm{~g} . \mathrm{L}^{-1}$, and are a factor of $\approx 2$. They are $0.0214(7) \mathrm{min}^{-1}$ (static) and $0.0230(8) \mathrm{min}^{-1}$ (stirring) for [U] $=60$ g. $\mathrm{L}^{-1}$, and are only a factor of $\approx 1.07$. For the latter, the influence of the magnetic stirring is quite limited, since the kinetics gain is about $7 \%$. The kinetics of the precipitation is thus directly correlated to the concentration of uranium in the aqueous nitric acid solution. Without stirring, this result is not surprising as for a greater concentration, the reagent put in touch is less limited by diffusion. The maximum precipitation yield $(99 \% \mathrm{U})$ is reached after $\approx 3$ hours for $[\mathrm{U}]=40$ and $60 \mathrm{~g} . \mathrm{L}^{-1}$, under stirring conditions. However, we notice that the kinetics of precipitation remains quite slow and requires a reaction time of 3-4 hours for getting the maximal yield.

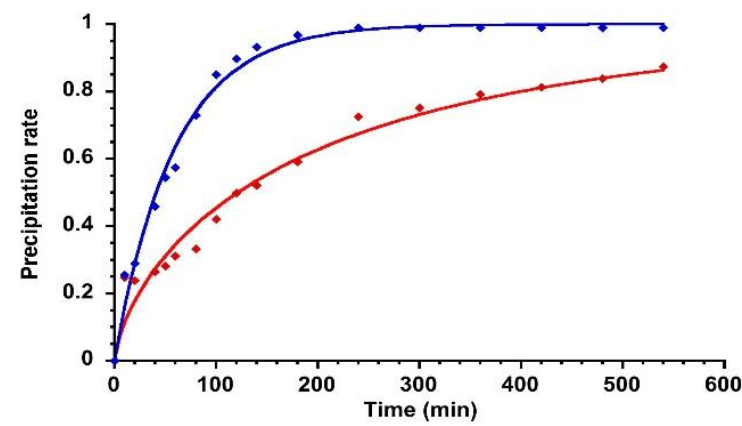

- no stirring

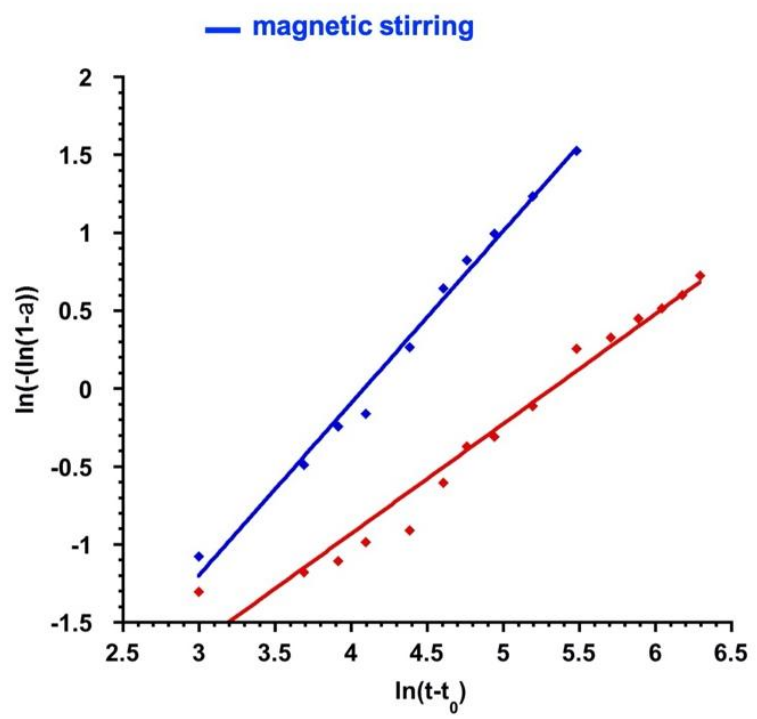

Figure 6: (top) Kinetics curve of formation of the $\left(\mathrm{UO}_{2}\right)(\text { adam })_{2}\left(\mathrm{NO}_{3}\right)_{2} \cdot 2$ (adam) (1) precipitate for $\mathrm{U}$ concentration at 20 g. $\mathrm{L}^{-1}$ under static conditions (red) and magnetic stirring (blue) in $\mathrm{HNO}_{3} 0.5 \mathrm{M}$ (at $50^{\circ} \mathrm{C}$ ), with molar ratio ligand/U $=5$. (bottom) Sharp-Hancock plot from linear regression of the Avrami-Erofe'ev equation $(\ln [-\ln (1-\alpha)]=n \ln (k)+n \ln (t))$. 
The Avrami parameters are in the range 0.7-1.1 (Table 3), with higher values for the stirring conditions (in the range 0.9-1.1) and lower values for the static conditions (in the range 0.7$0.9)$. According to previous data from literature, ${ }^{44,54}$ the crystallization mechanisms would be controlled by the diffusion of species for an Avrami exponent in the range 0.6-0.8, whereas it is controlled for reaction of species on the crystal surface if the Avrami exponent is in the range 1.0-1.1. This study confirms these two mechanisms: under static conditions, the kinetics of precipitation would be limited by a diffusion-controlled mechanism, and under stirring conditions, it would be limited by phase-boundary-controlled reaction.

Table 3: Kinetics parameters extracted from the curve fits from the Avrami-Erofe'ev equation and Sharp-Hancock plots describing the crystallization of $\left(\mathrm{UO}_{2}\right)(\text { adam })_{2}\left(\mathrm{NO}_{3}\right)_{2} \cdot 2$ (adam) (1). The fitting was performed using Kaleidagraph 4.5.

\begin{tabular}{|c|c|c|c|c|c|c|}
\hline & \multicolumn{2}{|c|}{$[\mathbf{U}]=20$ g. $\mathbf{L}^{-1}$} & \multicolumn{2}{|c|}{$[\mathrm{U}]=40$ g. $\mathrm{L}^{-1}$} & \multicolumn{2}{|c|}{$[\mathrm{U}]=60 \mathrm{~g} \cdot \mathrm{L}^{-1}$} \\
\hline $\begin{array}{l}\text { Avrami- } \\
\text { Erofe'ev }\end{array}$ & no stirring & stirring & no stirring & stirring & no stirring & stirring \\
\hline$k\left(\min ^{-1}\right)$ & $0.0049(3)$ & $0.0168(7)$ & $0.0101(4)$ & $0.0203(6)$ & $0.0214(7)$ & $0.0230(8)$ \\
\hline$n$ & $0.71(5)$ & $0.99(7)$ & $0.71(4)$ & $1.00(5)$ & $0.88(4)$ & $1.08(7)$ \\
\hline${ }^{*} R^{2}$ & 0.970 & 0.988 & 0.986 & 0.994 & 0.993 & 0.989 \\
\hline Sharp-Hancock & no stirring & stirring & no stirring & stirring & no stirring & stirring \\
\hline$k\left(\min ^{-1}\right)$ & $0.0049(5)$ & $0.0168(3)$ & $0.0109(6)$ & $0.0219(5)$ & $0.02286(5)$ & $0.0242(7)$ \\
\hline$n$ & $0.71(4)$ & $1.10(4)$ & $0.77(4)$ & $1.05(6)$ & $0.93(4)$ & $0.90(5)$ \\
\hline${ }^{*} R^{2}$ & 0.966 & 0.989 & 0.963 & 0.969 & 0.976 & 0.966 \\
\hline
\end{tabular}

${ }^{*} R^{2}$ : correlation coefficient from the kinetics curves fittings.

This study shows that the acetamide bearing an adamantyl group (i.e N-(1adamantyl)acetamide) could be a good candidate for precipitating uranyl nitrate from highly acidic nitric acid aqueous solutions. When the adam/U ratio reaches to $5 / 1$, one observes high yields for uranium precipitation with values in the range 96-99\% for nitric acid concentrations $1-5 \mathrm{M}$. It is well-known that the classical precipitating agent used in the spent nuclear fuel recycling is the oxalic acid molecule, which is very efficient for its rapid reaction with tetravalent actinide, such as plutonium(IV) with very high yields $(>99 \% \mathrm{Pu})$. Unfortunately, in the case of uranyl nitrate aqueous solution, the precipitation yield was observed to decrease drastically. For instance, previous investigations, ${ }^{55}$ have shown the formation of a powdered product of hydrated uranyl oxalate type $\left(\mathrm{UO}_{2}\left[\mathrm{C}_{2} \mathrm{O}_{4}\right]\left(\mathrm{H}_{2} \mathrm{O}\right) \cdot 2 \mathrm{H}_{2} \mathrm{O}\right)$ after mixing oxalic acid in a nitric acid aqueous solution containing uranyl nitrate. Optimal 
precipitation yield was found to be less than $83 \%_{\mathrm{U}}$ (remaining $[\mathrm{U}]=4.0 \mathrm{~g} . \mathrm{L}^{-1}$ ), from an uranyl nitrate concentration $\left[23.8\right.$ g. $\left.\mathrm{L}^{-1}\right]$ in $\mathrm{HNO}_{3}(2 \mathrm{M})$ aqueous solution at ambient temperature. If the precipitation of $\mathrm{UO}_{2}\left[\mathrm{C}_{2} \mathrm{O}_{4}\right]\left(\mathrm{H}_{2} \mathrm{O}\right) \cdot 2 \mathrm{H}_{2} \mathrm{O}$ appeared after a few minutes, the maximal yield is obtained after several hours. ${ }^{55}$ By comparison, our study indicates a precipitation of uranyl nitrate complex within roughly the same reaction time but, with a better precipitation yield (up to $99 \%$ U).

Nevertheless, this slow precipitation kinetics drawback is not reported when using Ncyclohexyl-2-pyrrolidone (NCP), for which a pioneering work describes the formation of an uranyl nitrate coordination complex $\mathrm{UO}_{2}\left(\mathrm{NO}_{3}\right)_{2}(\mathrm{NCP})_{2}$ with reaction yield of $68 \%_{\mathrm{U}}$, from an initial $\mathrm{NCP} / \mathrm{U}=3.6$ and $[\mathrm{U}]=50 \mathrm{~g} . \mathrm{L}^{-1}{ }^{7}$. Further investigations on this NCP-U(VI) system have shown a robust precipitation route since high specifications with reaction yields $>99 \% \mathrm{U}$ have been described from highly concentrated uranyl nitrate solution, i.e 238 g.L ${ }^{-1}$, NCP/U ratio $>3$ in $\mathrm{HNO}_{3} 3 \mathrm{M}^{56}$ The main difference is the kinetics of the precipitation of uranyl cation between the NCP and adam systems. Indeed, the precipitation of the NCP uranyl nitrate complex is complete after a few minutes at room temperature only, ${ }^{56}$ but requires a reaction time for several hours for the production of the complex 1 with adam ligand from solutions containing $[\mathrm{U}]=40$ or $60 \mathrm{~g} . \mathrm{L}^{-1}$ at $50^{\circ} \mathrm{C}$ (with $\mathrm{HNO}_{3} 0.5 \mathrm{M}$ ). The solubility of the organic complexing agent in water might be considered for explaining such different kinetic reactivities. The NCP molecule is a viscous liquid, which possesses a high miscibility with water, ${ }^{9}$ whereas oxalic acid and $\mathrm{N}$-(1-adamantyl)acetamide) reactants are powdered compounds. The water solubility of oxalic acid is known to be quite high $\left(90-100 \mathrm{~g} . \mathrm{L}^{-1}\right.$ at room temperature) and we estimated that of $\mathrm{N}$-(1-adamantyl)acetamide), which was found to be very low ( $\approx 1-2$ g. $\mathrm{L}^{-1}$ at room temperature). These ligand solubility considerations may thus control the slow formation of the $\left(\mathrm{UO}_{2}\right)(\text { adam })_{2}\left(\mathrm{NO}_{3}\right)_{2} \cdot 2$ (adam) (1) complex, compared to that of the NCP uranyl complex. This drastic kinetics difference strongly limits the potential use of the $\mathrm{N}$-(1-adamantyl)acetamide molecule as precipitating agent for industrial applications.

\section{Thermal analysis}

The thermal treatment under air atmosphere has been analyzed, only for the complex $\mathbf{1}$, in order to study the thermal transition of this uranyl complex under its oxide form. The thermal decomposition of complex $\mathbf{1}$ has been characterized by in-situ powder X-ray diffraction (Figure 7). This experiment shows multiple phase transformation steps. Bragg peaks of the phase 1 persist up to $200^{\circ} \mathrm{C}$. At this temperature, a new transient crystalline product (red 
diffraction patterns - Figure 7) appeared with a new set of peaks located at $d=10.03,8.96$, 6.67 and $7.62 \AA$, for the lowest angle values. This structural transformation is related to a first weight loss of $3 \%$, after heating up to $170^{\circ} \mathrm{C}$, reported on the thermogravimetric curve (Figure S9). Between 200 and $400^{\circ} \mathrm{C}$, new broad Bragg peaks (blue diffraction patterns Figure 7) are visible with $d=3.33,2.86$ and $1.99 \AA$, indicating the crystallization of a second badly crystalline product, related to the formation of $\mathrm{UO}_{2}$ fluorite type compound (Figure S11). A remarkable and unexpected transient reduction of the uranium is observed during the decomposition of the coordination organic-inorganic complex. Indeed, previous thermal decompositions have been reported for some uranyl coordination complexes, such as uranyl terephthalate, ${ }^{57}$ uranyl pyromellitates ${ }^{58}$ or uranyl mellitate, ${ }^{59}$ for instance. The thermal transformation of these initial complexes went directly to the formation of the uranium oxide $\mathrm{U}_{3} \mathrm{O}_{8}$ under air atmosphere, without through the generation of a transient $\mathrm{UO}_{2}$ phase. For the present study, the appearance of the $\mathrm{UO}_{2}$ oxide could be correlated to the air combustion of the organic part (which is present with a larger $\mathrm{L} / \mathrm{U}$ ratio compared to the previous examples), ${ }^{57-59}$ likely into transient $\mathrm{CO}$ species, inducing high concentration of these evacuating gases and provoking the temporary reduction of uranium, crystallizing with the fluorite structure. This intermediate uranium reduction during thermal treatment is therefore quite specific of the degradation of compound 1. The fluorite phase is then classically transformed when further heating under air into the $\mathrm{U}_{3} \mathrm{O}_{8}$ form. ${ }^{60}$ Indeed, from $400^{\circ} \mathrm{C}$, the crystallization of $\alpha-\mathrm{U}_{3} \mathrm{O}_{8}$ is clearly observed with peaks intensity increasing with temperature. The thermogravimetric curve of this complex (Figure S9) presents weight loss events between 120 and $500{ }^{\circ} \mathrm{C}$. The remaining weight value is $24.1 \%$, in good agreement with the expected one (24.0\%wt.), for $\mathrm{U}_{3} \mathrm{O}_{8}$ as final phase at $800^{\circ} \mathrm{C}$.

BET surface area (using krypton adsorption) of the resulting uranium oxide after heating at $800^{\circ} \mathrm{C}$, was measured at $3.9( \pm 0.5) \mathrm{m}^{2} \cdot \mathrm{g}^{-1}$. This value strongly depends on the calcination conditions but seems to be a bit high compared to previous studies on $\mathrm{U}_{3} \mathrm{O}_{8}$ compounds. ${ }^{61,62}$ Scanning electron microscopy of the calcined complex 1 at $800^{\circ} \mathrm{C}$ indicates the preservation of large blocks $(50 \mu \mathrm{m})$, but cracks and holes are visible, due to the gaseous evacuation of the degradation products from the organic ligand (Figure S10). 


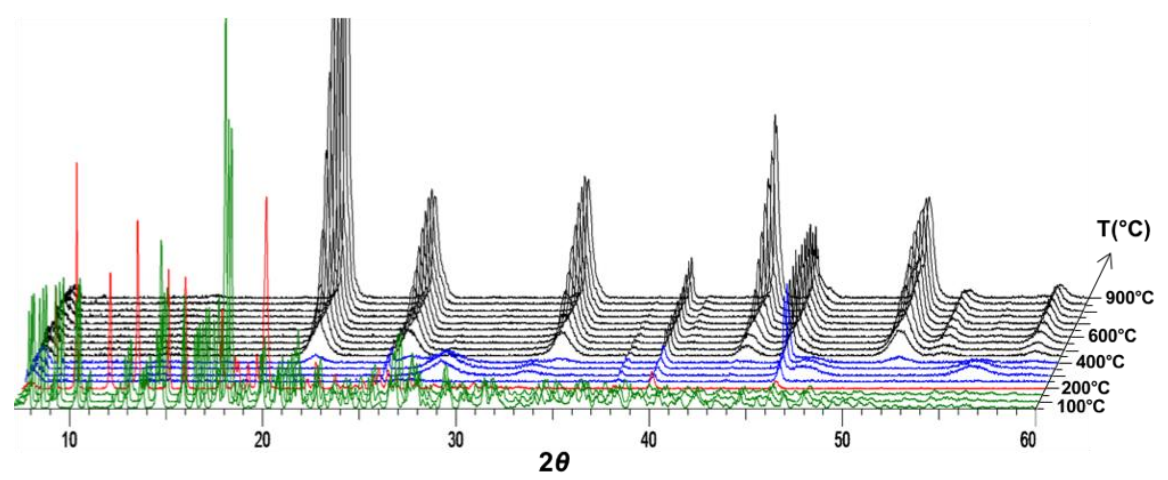

Figure 7: Evolution of the powder XRD patterns as a function of temperature for the $\left(\mathrm{UO}_{2}\right)(\text { adam })_{2}\left(\mathrm{NO}_{3}\right)_{2} \cdot 2$ (adam) (1) (heating rate $5^{\circ} \mathrm{C} \cdot \mathrm{min}^{-1}$ and scans collected every $50^{\circ} \mathrm{C}$, air atmosphere). XRD patterns in green: $\left(\mathrm{UO}_{2}\right)(\text { adam })_{2}\left(\mathrm{NO}_{3}\right)_{2} \cdot 2$ (adam) (1) phase; red: unknown phase; blue: transient fluorite-like $\mathrm{UO}_{2}$ phase; black: $\alpha-\mathrm{U}_{3} \mathrm{O}_{8}$ phase.

\section{Conclusion}

In summary, the ability of the $\mathrm{N}$-(1-adamantyl)acetamide molecule to precipitate the uranyl cation has been examined in the view of a general actinide recycling process. In a wide range of highly concentrated nitric acid solutions $(0.5-5 \mathrm{M})$, this organic species is able to react with the actinyl cation, to form a crystalline coordination complex, $\left(\mathrm{AnO}_{2}\right)(\text { adam })_{2}\left(\mathrm{NO}_{3}\right)_{2} \cdot 2$ (adam) $(\mathrm{An}=\mathrm{U}(\mathbf{1})$ or $\mathrm{Pu}(\mathbf{2}))$, obtained with high yield (up to $99 \% \mathrm{An}$, when L/An ratio is 5 ). The kinetics investigations have shown that the precipitation reaction is rather slow and completed after several hours (3-4 h) for the compound 1 even under stirring. This could be related to the rather weak solubility of the powdered $\mathrm{N}$-(1-adamantyl)acetamide molecule in water, which inhibits the rapid reaction with the uranyl cations. The thermal degradation of the $\left(\mathrm{UO}_{2}\right)(\text { adam })_{2}\left(\mathrm{NO}_{3}\right)_{2} \cdot 2$ (adam) compound (1) showed a decomposition in three steps with the transient formation of an crystalline unidentified phase, followed by a reduction process from $200^{\circ} \mathrm{C}$, with the crystallization of fluorite-type $\mathrm{UO}_{2}$, and finally transformed into uranium oxide $\mathrm{U}_{3} \mathrm{O}_{8}$ from $400^{\circ} \mathrm{C}$, under air atmosphere.

The N-(1-adamantyl)acetamide ligand has thus showed interesting properties for the quantitative precipitation of uranyl(VI) cation in nitric acid, which can be extended to the use of the analogous element, plutonyl(VI) cation (2). This chemical reactivity have been restricted to the use of hexavalent state of actinide and further investigations will be required in order to examine the precipitation behavior with tetravalent actinide elements. 


\section{Acknowledgements}

The authors would like to thank Mrs. Nora Djelal, Laurence Burylo, Philippe Devaux and Pr Lydie Pelinski for their assistances with the synthesis, SEM images, XRD powder patterns measurements (UCCS). The "Fonds Européen de Développement Régional (FEDER)", "CNRS", "Région Hauts de France" and "Ministère de l'Education Nationale de l'Enseignement Supérieur et de la Recherche" are acknowledged for the funding of X-ray diffractometers and ICP-AES apparatus from the Chevreul Institute platform. This work was part of the French National Research Agency (ANR) through the project “ASTUTE" (contract ANR-15-CE08-0011-01).

\section{Associated Content}

Supporting Information

Supplementary data (powder XRD pattern, thermogravimetric curves, IR spectra) associated with this article can be found in the online version.

Accession Codes

Crystallographic data for the structural analysis have been deposited with the Cambridge Crystallographic Data Centre, CCDC No. 1987462 for 1, 1987465 for 2. Copies of the data can be obtained free of charge on application to CCDC, 12 Union Road, Cambridge CB2 1EZ (fax: +44-1223-336-033; e-mail: data_request@ccdc.cam.ac.uk). 


\section{References.}

(1) Lanham, W. B.; Runion, T. C. PUREX PROCESS FOR PLUTONIUM AND URANIUM RECOVERY; ORNL-479(Del.), 4165457; 1949; p ORNL-479(Del.), 4165457. https://doi.org/10.2172/4165457.

(2) Science and Technology of Tributyl Phosphate. Vol. 3: Applications of Tributyl Phosphate in Nuclear Fuel Processing; Schulz, W. W., Ed.; CRC Press: Boca Raton, 1990.

(3) Reprocessing and Recycling of Spent Nuclear Fuel; Taylor, R., Ed.; Woodhead Publishing series in energy; Woodhead Publ./Elsevier: Amsterdam, 2015.

(4) Abraham, F.; Arab-Chapelet, B.; Rivenet, M.; Tamain, C.; Grandjean, S. Actinide Oxalates, Solid State Structures and Applications. Coord. Chem. Rev. 2014, 266-267, 28-68. https://doi.org/10.1016/j.ccr.2013.08.036.

(5) Grandjean, S.; Bérès, A.; Rousselle, J.; Maillard, C. Method for Co-Precipitation of Actinides in Different Oxidation States and Method for Preparation of Mixed Actinide Compounds. WO/2005/119699.

(6) Varga, T. R.; Sato, M.; Fazekas, Z.; Harada, M.; Ikeda, Y.; Tomiyasu, H. New Uranyl Nitrate Complex with N-Cyclohexyl-2-Pyrrolidone: A Promising Candidate for Nuclear Fuel Reprocessing. Inorg. Chem. Commun. 2000, 3 (11), 637-639. https://doi.org/10.1016/S1387-7003(00)00123-4.

(7) Varga, T. R.; Bényei, A. C.; Fazekas, Z.; Tomiyasu, H.; Ikeda, Y. Molecular and Crystal Structure of Bis(N-Cyclohexyl-2-Pyrrolidone)Dioxouranium(VI) Nitrate. Inorg. Chim. Acta 2003, 342, 291-294. https://doi.org/10.1016/S0020-1693(02)011623.

(8) Koshino, N.; Harada, M.; Morita, Y.; Kiikuchi, T.; Ikeda, Y. Using Selective Precipitant for Uranyl Ions - Fundamental Studies for Evaluating the Precipitant Performance. Prog. Nucl. Energy 2005, 47 (1-4), 406-413. https://doi.org/10.1016/j.pnucene.2005.05.040.

(9) Ikeda, Y.; Wada, E.; Harada, M.; Chikazawa, T.; Kikuchi, T.; Mineo, H.; Morita, Y.; Nogami, M.; Suzuki, K. A Study on Pyrrolidone Derivatives as Selective Precipitant for Uranyl Ion in HNO3. J. Alloys Compd. 2004, 374 (1-2), 420-425. https://doi.org/10.1016/j.jallcom.2003.11.050.

(10) Kazama, H.; Tsushima, S.; Ikeda, Y.; Takao, K. Molecular and Crystal Structures of Uranyl Nitrate Coordination Polymers with Double-Headed 2-Pyrrolidone Derivatives. Inorg. Chem. $\quad 56$ 2017, (21), 13530-13534. https://doi.org/10.1021/acs.inorgchem.7b02250.

(11) Morita, Y.; Takao, K.; Kim, S.-Y.; Kawata, Y.; Harada, M.; Nogami, M.; Nishimura, K.; Ikeda, Y. Development of Advanced Reprocessing System Based on Precipitation Method Using Pyrrolidone Derivatives as Precipitants: - Precipitation Behavior of $\mathrm{U}(\mathrm{VI}), \mathrm{Pu}(\mathrm{IV})$, and $\mathrm{Pu}(\mathrm{VI})$ by Pyrrolidone Derivatives with Low Hydrophobicity-. $J$. Nucl. Sci. Technol. 2009, $46 \quad$ (12), $1129-1136$. https://doi.org/10.1080/18811248.2009.9711625.

(12) Kim, S.-Y.; Takao, K.; Haga, Y.; Yamamoto, E.; Kawata, Y.; Morita, Y.; Nishimura, K.; Ikeda, Y. Molecular and Crystal Structures of Plutonyl(VI) Nitrate Complexes with $N$-Alkylated 2-Pyrrolidone Derivatives: Cocrystallization Potentiality of $\mathrm{U}^{\mathrm{VI}}$ and $\mathrm{Pu}$ VI. Cryst. Growth Des. 2010, 10 (5), 2033-2036. https://doi.org/10.1021/cg100015t.

(13) Ansari, S. A.; Pathak, P.; Mohapatra, P. K.; Manchanda, V. K. Chemistry of Diglycolamides: Promising Extractants for Actinide Partitioning. Chem. Rev. 2012, 112 (3), 1751-1772. https://doi.org/10.1021/cr200002f. 
(14) Musikas, C. Solvent Extraction for the Chemical Separations of the 5f Elements. Inorg. Chim. Acta 1987, 140, 197-206. https://doi.org/10.1016/S0020-1693(00)81087-7.

(15) Martin-Gil, J.; Martin-Gil, F. J.; Perales, A.; Fayos, J.; Martínez-Ripoll, M. Bis(N,NDimethylformamide)Dinitratodioxouranium(VI), $\mathrm{C}_{6} \mathrm{H}_{14} \mathrm{~N}_{4} \mathrm{O}_{10} \mathrm{U}$. Acta Crystallogr. $C$ Cryst. Struct. Commun. 1983, $39 \quad$ (1), 44-45. https://doi.org/10.1107/S0108270183003534.

(16) Loubert, G.; Volkringer, C.; Henry, N.; Arab-Chapelet, B.; Delahaye, T.; Loiseau, T. Structural Studies of a Series of Uranyl Alkylacetamides and Piracetam Complexes Obtained in Nitric Acid Aqueous Solution. Polyhedron 2017, 138, 7-12. https://doi.org/10.1016/j.poly.2017.09.006.

(17) Charpin, P.; Lance, M.; Nierlich, M.; Vigner, D.; Descouls, N.; Musikas, C. Structure Du Bis(N,N-Dibutyldodécanamide)Dinitratodioxouranium(VI). Acta Crystallogr. C Cryst. Struct. Commun. 1986, 42 (5), 560-563. https://doi.org/10.1107/S0108270186095409.

(18) Charpin, P.; Lance, M.; Nierlich, M.; Vigner, D.; Charbonnel, M. C.; Musikas, C. Complexes of Uranyl Nitrate and Dialkyldiamides: Structures of Dinitratodioxo[N,N,N',N'-Tetrabutyl-1,2-Phenylenebis(Oxyacetamide)-

O,O']Uranium(VI) and Catena-Poly\{[Dinitratodioxouranium(VI)]- $\mu-\left(\mathrm{N}, \mathrm{N}, \mathrm{N}^{\prime}, \mathrm{N}^{\prime},-\right.$ Tetrabutylglutaramide-O:O')\}. Acta Crystallogr. C Cryst. Struct. Commun. 1987, 43 (3), 442-445. https://doi.org/10.1107/S0108270187095441.

(19) Charpin, P.; Lance, M.; Nierlich, M.; Vigner, D.; Musikas, C. Structure Du Bis(N,NDi-n-Butyl Diméthyl-3,3 Butanamide)Dinitratodioxouranium(VI). Acta Crystallogr. C Cryst. Struct. Commun. 1987, 43 (2), 231-233. https://doi.org/10.1107/S010827018709632X.

(20) Van Vuuren, C. P. J.; Van Rooyen, P. H. The Solid State Chemistry of Uranium. Part 2. Structure and Thermal Reactions of $\mathrm{UO}_{2}\left(\mathrm{NO}_{3}\right)_{2} \cdot 2$ tmu. Inorg. Chim. Acta 1988, 142 (1), 151-152. https://doi.org/10.1016/S0020-1693(00)80673-8.

(21) Cao, Z.; Wang, H.; Gu, J.; Zhu, L.; Yu, K. Structure of Bis( $(\varepsilon-$ Caprolactam)Dinitratodioxouranium(VI). Acta Crystallogr. C Cryst. Struct. Commun. 1993, 49 (11), 1942-1943. https://doi.org/10.1107/S0108270193004536.

(22) Cao, Z.; Qi, T.; Zhu, L.; Zhang, D.-C.; Zhou, R.; Yu, K.-B. Bis(1,3Dibutylimidazolidin-2-One-O)Bis(Nitrato- $O, O$ ')Dioxouranium(VI). Acta Crystallogr. C Cryst. Struct. Commun. 1999, 55 (8), 1270-1272. https://doi.org/10.1107/S0108270199004916.

(23) Lumetta, G. J.; McNamara, B. K.; Rapko, B. M.; Sell, R. L.; Rogers, R. D.; Broker, G.; Hutchison, J. E. Synthesis and Characterization of Mono- and Bis(Tetraalkylmalonamide)Uranium(VI) Complexes. Inorg. Chim. Acta 2000, 309 (1-2), 103-108. https://doi.org/10.1016/S0020-1693(00)00253-X.

(24) Kannan, S.; Deb, S. B.; Gamare, J. S.; Drew, M. G. B. Coordination and Separation Studies of the Uranyl Ion with Iso-Butyramide Based Ligands: Synthesis and Structures of $\quad\left[\mathrm{UO}_{2}\left(\mathrm{NO}_{3}\right)_{2}\left(\mathrm{IC}_{3} \mathrm{H}_{7} \mathrm{CON}\left\{\mathrm{iC}_{4} \mathrm{H}_{9}\right\}_{2}\right)_{2}\right]$ and $\left[\mathrm{UO}_{2}\left(\mathrm{C}_{6} \mathrm{H}_{5} \mathrm{COCHCOC}_{6} \mathrm{H}_{5}\right)_{2}\left(\mathrm{IC}_{3} \mathrm{H}_{7} \mathrm{CON}\left\{\mathrm{iC}_{3} \mathrm{H}_{7}\right\}_{2}\right)\right]$. Polyhedron 2008, 27 (12), 25572562. https://doi.org/10.1016/j.poly.2008.05.010.

(25) Deb, S. B.; Gamare, J. S.; Kannan, S.; Drew, M. G. B. Uranyl(VI) and Lanthanum(III) Thio-Diglycolamides Complexes: Synthesis and Structural Studies Involving Nitrate Complexation. Polyhedron 2009, $28 \quad$ (13), 2673-2678. https://doi.org/10.1016/j.poly.2009.06.001.

(26) Kannan, S.; Deb, S. B.; Drew, M. G. B. Synthesis, Structural and Emission Studies of a Bis (Carbamoyl Methyl) Sulfone Complex of Uranyl Nitrate. Inorg. Chem. Commun. 2011, 14 (1), 225-227. https://doi.org/10.1016/j.inoche.2010.10.028. 
(27) Wahu, S.; Berthet, J.-C.; Thuéry, P.; Guillaumont, D.; Ephritikhine, M.; Guillot, R.; Cote, G.; Bresson, C. Structural Versatility of Uranyl(VI) Nitrate Complexes That Involve the Diamide Ligand $\mathrm{Et}_{2} \mathrm{~N}(\mathrm{C}=\mathrm{O})\left(\mathrm{CH}_{2}\right) \mathrm{n}(\mathrm{C}=\mathrm{O}) \mathrm{NEt}_{2}(0 \leq \mathrm{n} \leq 6)$. Eur. J. Inorg. Chem. 2012, 2012 (23), 3747-3763. https://doi.org/10.1002/ejic.201200243.

(28) Rodrigues, F.; Ferru, G.; Berthon, L.; Boubals, N.; Guilbaud, P.; Sorel, C.; Diat, O.; Bauduin, P.; Simonin, J. P.; Morel, J. P.; Morel-Desrosiers, N.; Charbonnel, M. C. New Insights into the Extraction of Uranium(VI) by an N,N-Dialkylamide. Mol. Phys. 2014, 112 (9-10), 1362-1374. https://doi.org/10.1080/00268976.2014.902139.

(29) Vats, B. G.; Kannan, S.; Pius, I. C.; Noronha, D. M.; Maity, D. K.; Drew, M. G. B. Synthetic, Structural, Extraction and Theoretical Studies of Uranyl Nitrate DithioDiglycolamide Compounds. Polyhedron 2014, 75, 81-87. https://doi.org/10.1016/j.poly.2014.03.015.

(30) Das, D.; Vats, B. G.; Kannan, S.; Kumar, M.; Sureshkumar, M. K. Synthetic and Structural Studies of Piperidine Carboxamide Uranyl Ion Complexes. Polyhedron 2014, 81, 39-44. https://doi.org/10.1016/j.poly.2014.05.037.

(31) Bisson, J.; Dehaudt, J.; Charbonnel, M.-C.; Guillaneux, D.; Miguirditchian, M.; Marie, C.; Boubals, N.; Dutech, G.; Pipelier, M.; Blot, V.; Dubreuil, D. 1,10-Phenanthroline and Non-Symmetrical 1,3,5-Triazine Dipicolinamide-Based Ligands For Group Actinide Extraction. Chem. Eur. J. 2014, 20 (25), 7819-7829. https://doi.org/10.1002/chem.201402266.

(32) Yuan, L.-Y.; Sun, M.; Mei, L.; Wang, L.; Zheng, L.-R.; Gao, Z.-Q.; Zhang, J.; Zhao, Y.-L.; Chai, Z.-F.; Shi, W.-Q. New Insight of Coordination and Extraction of Uranium(VI) with N-Donating Ligands in Room Temperature Ionic Liquids: $N, N^{\prime}-$ Diethyl- $N, N^{\prime}$-Ditolyldipicolinamide as a Case Study. Inorg. Chem. 2015, 54 (4), 19921999. https://doi.org/10.1021/ic502890w.

(33) Acher, E.; Hacene Cherkaski, Y.; Dumas, T.; Tamain, C.; Guillaumont, D.; Boubals, N.; Javierre, G.; Hennig, C.; Solari, P. L.; Charbonnel, M.-C. Structures of Plutonium(IV) and Uranium(VI) with $N, N$-Dialkyl Amides from Crystallography, $\mathrm{X}$ Ray Absorption Spectra, and Theoretical Calculations. Inorg. Chem. 2016, 55 (11), 5558-5569. https://doi.org/10.1021/acs.inorgchem.6b00592.

(34) Serezhkina, L. B.; Grigor'ev, M. S.; Novikov, S. A.; Kolotilina, M. A.; Serezhkin, V. N. Complex of Uranyl Citraconate with Dimethylacetamide: Synthesis and Structure. Radiochem. 2017, 59 (1), 35-40. https://doi.org/10.1134/S1066362217010039.

(35) Alyapyshev, M.; Babain, V.; Tkachenko, L.; Gurzhiy, V.; Zolotarev, A.; Ustynyuk, Y.; Gloriozov, I.; Lumpov, A.; Dar'in, D.; Paulenova, A. Complexes of Uranyl Nitrate with 2,6-Pyridinedicarboxamides: Synthesis, Crystal Structure, and DFT Study: Complexes of Uranyl Nitrate with 2,6-Pyridinedicarboxamides: Synthesis, Crystal Structure, and DFT Study. Z. Anorg. Allg. Chem. 2017, 643 (9), 585-592. https://doi.org/10.1002/zaac.201700063.

(36) Acher, E.; Dumas, T.; Tamain, C.; Boubals, N.; Solari, P. L.; Guillaumont, D. Inner to Outer-Sphere Coordination of Plutonium(IV) with N,N-Dialkyl Amide: Influence of Nitric Acid. Dalton Trans. 2017, 46 (12), 3812-3815. https://doi.org/10.1039/C7DT00031F.

(37) SAINT Plus Version 8.34a, Bruker Analytical X-Ray Systems. Brucker Analytical Xray Systems: Madison, WI, 2008. MADISON, WI. 2014.

(38) Sheldrick, G. M. SADABS, Bruker-Siemens Area Detector Absorption and Other Correction, Version 2014/5. Brucker-Siemens Area detector Absorption and Other Correction. Bruker, MADISON, WI 2015b. 
(39) Sheldrick, G. M. A Short History of SHELX. Acta Crystallographica Section A $\begin{array}{llllll}\text { Foundations of } \quad \text { Crystallography 2008, } 64 & \text { (1), }\end{array}$ https://doi.org/10.1107/S0108767307043930.

(40) Dolomanov, O. V.; Bourhis, L. J.; Gildea, R. J.; Howard, J. A. K.; Puschmann, H. OLEX2: A Complete Structure Solution, Refinement and Analysis Program. J. Appl. Crystallogr. 2009, 42 (2), 339-341. https://doi.org/10.1107/S0021889808042726.

(41) Petříček, V.; Dušek, M.; Palatinus, L. Crystallographic Computing System JANA2006: General Features. Zeitschrift für Kristallographie - Crystalline Materials 2014, 229 (5). https://doi.org/10.1515/zkri-2014-1737.

(42) Charushnikova, I. A.; Krot, N. N.; Starikova, Z. A. Crystal Structure of a Complex of $\mathrm{Pu}(\mathrm{VI})$ Nitrate with Triphenylphosphine Oxide, $\left[\mathrm{PuO}_{2}\left(\mathrm{NO}_{3}\right)_{2}\left(\mathrm{OP}\left(\mathrm{C}_{6} \mathrm{H}_{5}\right)_{3}\right)_{2}\right]$. Radiochem. 2007, 49 (6), 561-564. https://doi.org/10.1134/S1066362207060021.

(43) Gaunt, A. J.; May, I.; Neu, M. P.; Reilly, S. D.; Scott, B. L. Structural and Spectroscopic Characterization of Plutonyl(VI) Nitrate under Acidic Conditions. Inorg. Chem. 2011, 50 (10), 4244-4246. https://doi.org/10.1021/ic200525u.

(44) Finney, E. E.; Finke, R. G. Is There a Minimal Chemical Mechanism Underlying Classical Avrami-Erofe'ev Treatments of Phase-Transformation Kinetic Data? Chem. Mater. 2009, 21 (19), 4692-4705. https://doi.org/10.1021/cm9018716.

(45) Jensen, K. M. Ø.; Tyrsted, C.; Bremholm, M.; Iversen, B. B. In Situ Studies of Solvothermal Synthesis of Energy Materials. ChemSusChem 2014, 7 (6), 1594-1611. https://doi.org/10.1002/cssc.201301042.

(46) Thompson, R. W.; Dyer, A. Mathematical Analyses of Zeolite Crystallization. Zeolites 1985, 5 (4), 202-210. https://doi.org/10.1016/0144-2449(85)90086-7.

(47) Norby, P. Hydrothermal Conversion of Zeolites: An in Situ Synchrotron X-Ray Powder Diffraction Study. J. Am. Chem. Soc. 1997, 119 (22), 5215-5221. https://doi.org/10.1021/ja964245g.

(48) Francis, R. J.; O’Brien, S.; Fogg, A. M.; Halasyamani, P. S.; O’Hare, D.; Loiseau, T.; Férey, G. Time-Resolved In-Situ Energy and Angular Dispersive X-Ray Diffraction Studies of the Formation of the Microporous Gallophosphate ULM-5 under Hydrothermal Conditions. J. Am. Chem. Soc. 1999, 121 (5), 1002-1015. https://doi.org/10.1021/ja982441c.

(49) Vistad, Ø. B.; Akporiaye, D. E.; Lillerud, K. P. Identification of a Key Precursor Phase for Synthesis of SAPO-34 and Kinetics of Formation Investigated by in Situ X-Ray Diffraction. J. Phys. Chem. B 2001, 105 (50), 12437-12447. https://doi.org/10.1021/jp0110758.

(50) Grandjean, D.; Beale, A. M.; Petukhov, A. V.; Weckhuysen, B. M. Unraveling the Crystallization Mechanism of CoAPO-5 Molecular Sieves under Hydrothermal Conditions. J. Am. Chem. Soc. 2005, 127 (41), 14454-14465. https://doi.org/10.1021/ja054014m.

(51) Millange, F.; Medina, M. I.; Guillou, N.; Férey, G.; Golden, K. M.; Walton, R. I. TimeResolved In Situ Diffraction Study of the Solvothermal Crystallization of Some Prototypical Metal-Organic Frameworks. Angew. Chem. Int. Ed. 2010, 49 (4), 763766. https://doi.org/10.1002/anie.200905627.

(52) Ahnfeldt, T.; Moellmer, J.; Guillerm, V.; Staudt, R.; Serre, C.; Stock, N. High- Throughput and Time- Resolved Energy- Dispersive X-Ray Diffraction (EDXRD) Study of the Formation of CAU- 1- $(\mathrm{OH})_{2}$ : Microwave and Conventional Heating. Chem. Eur. J. 2011, 17 (23), 6462-6468. https://doi.org/10.1002/chem.201003708.

(53) Cravillon, J.; Schröder, C. A.; Bux, H.; Rothkirch, A.; Caro, J.; Wiebcke, M. Formate Modulated Solvothermal Synthesis of ZIF-8 Investigated Using Time-Resolved in Situ 
X-Ray Diffraction and Scanning Electron Microscopy. CrystEngComm 2012, 14 (2), 492-498. https://doi.org/10.1039/C1CE06002C.

(54) Hancock, J. D.; Sharp, J. H. Method of Comparing Solid-State Kinetic Data and Its Application to the Decomposition of Kaolinite, Brucite, and $\mathrm{BaCO}_{3}$. J. Am. Ceram. Soc. 1972, 55 (2), 74-77. https://doi.org/10.1111/j.1151-2916.1972.tb11213.x.

(55) Leturcq, G.; Constenoble, S.; Grandjean, S. Uranyl Oxalate Solubility. Proceedings from ATALANTE 2008 Conference 2008, P3_16. https://inis.iaea.org/collection/NCLCollectionStore/_Public/40/007/40007523.pdf

(56) Morita, Y.; Kawata, Y.; Mineo, H.; Koshino, N.; Asanuma, N.; Ikeda, Y.; Yamasaki, K.; Chikazawa, T.; Tamaki, Y.; Kikuchi, T. A Study on Precipitation Behavior of Plutonium and Other Transuranium Elements with N-Cyclohexyl-2-Pyrrolidone for Development of a Simple Reprocessing Process. J. Nucl. Sci. Technol. 2007, 44 (3), 354-360. https://doi.org/10.1080/18811248.2007.9711294.

(57) Mihalcea, I.; Henry, N.; Bousquet, T.; Volkringer, C.; Loiseau, T. Six-Fold Coordinated Uranyl Cations in Extended Coordination Polymers. Cryst. Growth Des. 2012, 12 (9), 4641-4648. https://doi.org/10.1021/cg300853f.

(58) Mihalcea, I.; Henry, N.; Volkringer, C.; Loiseau, T. Uranyl-Pyromellitate Coordination Polymers: Toward Three-Dimensional Open Frameworks with Large Channel Systems. Cryst. Growth Des. 2012, 12 (1), 526-535. https://doi.org/10.1021/cg201509v.

(59) Volkringer, C.; Henry, N.; Grandjean, S.; Loiseau, T. Uranyl and/or Rare Earth Mellitates in Extended Organic-Inorganic Networks: A Unique Class of Heterometallic Cation-Cation Interaction with UVI=O-LnIII Bonding $(\mathrm{Ln}=\mathrm{Ce}, \mathrm{Nd}) . J$. Am. Chem. Soc. 2012, 134, 1275-1283.

(60) Rousseau, G.; Desgranges, L.; Charlot, F.; Millot, N.; Nièpce, J. C.; Pijolat, M.; Valdivieso, F.; Baldinozzi, G.; Bérar, J. F. A Detailed Study of $\mathrm{UO}_{2}$ to $\mathrm{U}_{3} \mathrm{O}_{8}$ Oxidation Phases and the Associated Rate-Limiting Steps. J. Nuclear Mater. 2006, 355 (1-3), 1020. https://doi.org/10.1016/j.jnucmat.2006.03.015.

(61) Chazel, V.; Houpert, P.; Ansoborlo, E. Effect of U3O8 Specific Surface Area on In Vitro Dissolution, Biokinetics, and Dose Coefficients. Radiat. Prot. Dosim. 1998, 79 (1), 39-42. https://doi.org/10.1093/oxfordjournals.rpd.a032434.

(62) Smith, M. L.; Leitnaker, J. M. Atmospheric Contamination of Uranium Dioxide Powder. Oak Ridge National Laboratory 1971. 